Section Editor

John J. Millichap, MD

James M. Noble, MD, MS

Correspondence to Dr. Noble:

jn2054@columbia.edu
Editorial, page 663

Supplemental data at Neurology.org
Education Research:

\section{Changing medical student perceptions of dementia}

\author{
An arts-centered experience
}

\section{ABSTRACT}

Background: Medical students' comfort level working with dementia is poorly understood, and may impact subsequent experiences with patients and caregivers. Early experiences that take place in a nonmedical setting may allow students to gain a more comprehensive understanding of quality of life and disease management in everyday life.

Methods: We studied Columbia University preclinical medical students' perceptions of dementia relative to attending a nonclinical art-centered, museum-based experience designed for people with dementia and their caregivers. Participants individually attended a single 90-minute museum-based art-centered program designed to engage patients with dementia and caregivers; programs are attended by 6-10 patient-caregiver dyads and led by trained museum educators at existing New York City sites including The Metropolitan Museum of Art, The Cloisters, The Studio Museum in Harlem, and The New-York Historical Society.

Results: The Dementia Attitudes Scale (DAS) was administered before and after the intervention (least favorable $=20$, neutral $=80$, most favorable $=140$ ). A total of 19 students completed baseline and postintervention DAS. At baseline, DAS mean = 97.4 (SD = 11.2). To limit bias of taking the test, 9 students completed a second preintervention DAS ( $\geq 1$ week apart); among these, DAS increased from $95.7(S D=7.7)$ to $98.7(S D=7.4)(p=0.09)$. Following the intervention, DAS favorably and significantly increased to 105.8 (SD =11.0) ( $p \leq 0.01$ for all comparisons, paired-samples $t$ test); greater differences were identified in comfort than knowledge of dementia.

Conclusions: Although further study is warranted to confirm findings, given the increasing availability of such programs, it is reasonable to consider inclusion of these alongside other nonclinical programs that are already part of medical school curricula. Neurology ${ }^{\circledR} 2015 ; 85: 739-741$

\section{GLOSSARY}

AD $=$ Alzheimer disease; $\mathbf{D A S}=$ Dementia Attitudes Scale

As the US population ages and Alzheimer disease (AD) develops in more Americans, health care professionals from all specialties will increasingly encounter dementia in everyday practice. ${ }^{1}$ Providers encounter unique challenges when working with people with $\mathrm{AD}$ and other forms of dementia, such as difficulty communicating with the patient and caregiver, establishing a doctor-patient relationship, and creating a treatment plan tailored to the unique home needs of the patient and caregiver. When these aspects are effectively addressed, they can have meaningful impact on long-term health outcomes in patients with $\mathrm{AD}$ and caregivers. ${ }^{2}$

Medical student encounters with patients with dementia and caregivers are typically based in hospitals or clinics during the course of routine training. Dementia knowledge can demonstrably improve following these typical experiences, ${ }^{3}$ but the impact on students' comfort and attitudes with dementia remains uncertain. Nonclinical dementia experiences are rarely offered, but can provide an opportunity for students to gain a more comprehensive understanding of the scope of dementia care and improve attitudes toward the disease.,

In New York City and elsewhere, existing art museum-based programs give patients with dementia and caregivers an opportunity to discuss art and make creations of their own, and offer visiting participants greater insight into dementia care and ways to maintain or enhance quality of life. We hypothesized that briefly participating in these nonclinical, art-centered experiences alongside patients with dementia and their caregivers improves preclinical medical student attitudes toward dementia.

From the College of Physicians \& Surgeons, Columbia University, New York, NY.

Go to Neurology.org for full disclosures. Funding information and disclosures deemed relevant by the authors, if any, are provided at the end of the article. 
METHODS Study design. We developed a pilot intervention study assessing preclinical medical student dementia attitudes; baseline assessments functioned as the control condition. Secure online survey responses were collected before and after the intervention.

Study population. The potential study cohort included all 167 preclinical first year medical students at the Columbia University College of Physicians and Surgeons, of whom approximately 70 were available in New York City during the summer 2013 enrollment period. The initial 20 responders to an e-mailed invitation were enrolled.

Intervention. Students attended one session of an existing local community-based arts program for people with dementia and their caregivers. These programs include Met Escapes at the Metropolitan Museum of Art, Sights and Scents at the Cloisters Museum, and Arts \& Minds programs at the Studio Museum of Harlem and the New York Historical Society. Each 90-minute program uses professionally trained staff to engage patients with dementia and caregivers in dialogue within museum galleries and in the studio while making creations of their own. Each student worked with one group of patients with dementia and caregivers (6-10 pairs) and participated in all program activities including gallery discussions and creative exercises on the assigned date.

Assessment. Students completed the Dementia Attitudes Scale (DAS) survey, ${ }^{5,6}$ a 20 -item questionnaire assessing perceptions of dementia, specifically comfort and knowledge. All students completed baseline surveys 2 weeks prior to their scheduled intervention. To explore the effect of time as well as the effect of repeated survey completion on the stability scores, 9 students filled out an additional baseline survey prior to the intervention.

\section{Figure Enrollment flowchart}

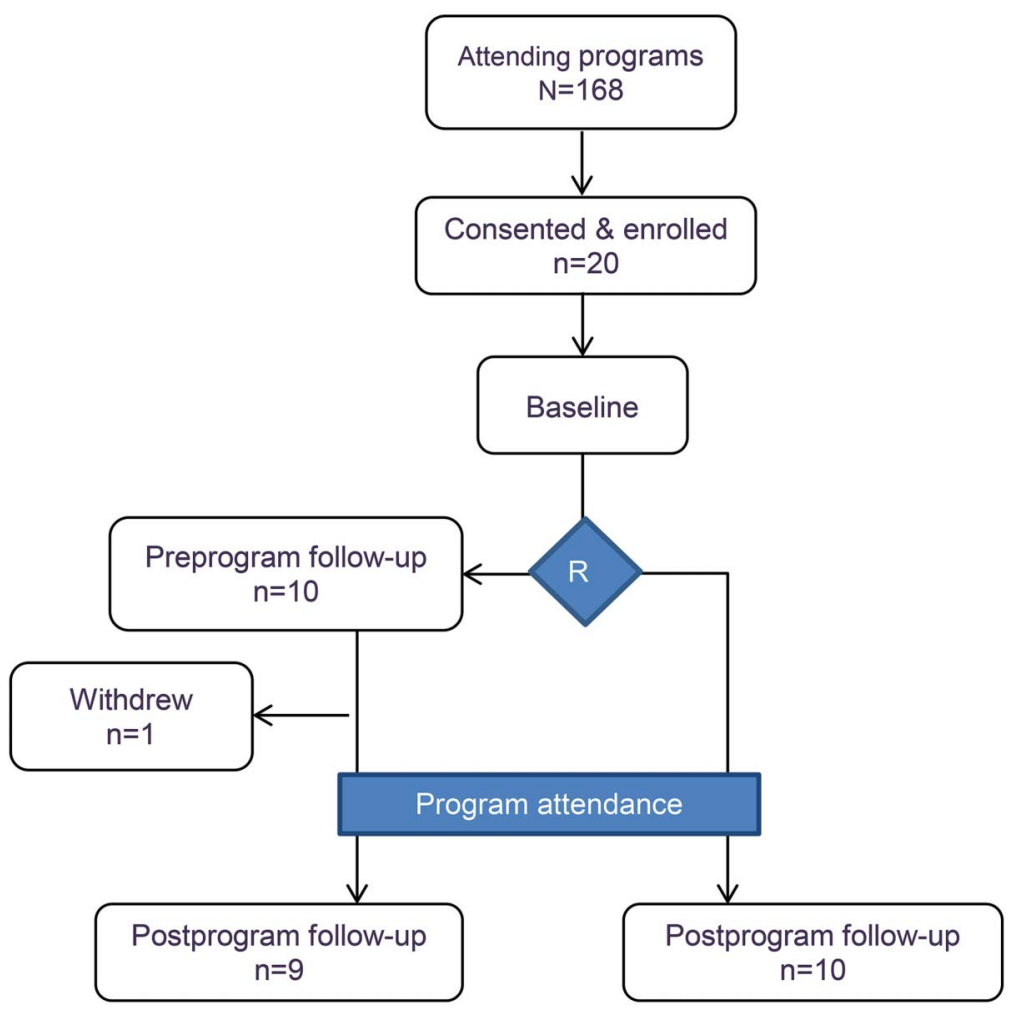

Enrollment process flowchart for study participants. $R$ = point of randomization to single or repeated preintervention Dementia Attitudes Scale assessments.
All students completed follow-up surveys 1-3 days after the intervention. The enrollment algorithm is detailed in the figure.

Standard protocol approvals, registrations, and patient consents. The study was approved by the Columbia University Medical Center Institutional Review Board. Consent forms were reviewed in person with H.J. Roberts, a classmate of the study participants. Given Dr. Noble's role as the school's neurology clerkship director, only H.J. Roberts was made aware of which students participated. Participants were paid a small monetary incentive for participation, travel expenditure, and completion of surveys.

Statistical analyses. All analyses used a paired-samples $t$ test comparison of means, SPSS v.19.

RESULTS The student ages ranged from 21 to 29 years, reflecting the overall class, including 14 women $(70 \%)$ and 8 ethnic minorities (40\%). Eleven of the 20 $(58 \%)$ had a relative with dementia, 3 had a history of working with patients with dementia, and 1 had experience as a caregiver of a relative with dementia.

At baseline, the DAS mean was 97.4 (SD 11.2). Among the 9 students who completed a second preintervention DAS ( $\geq 1$ week apart), DAS increased from 95.7 (SD 7.7) to 98.7 (SD 7.4) prior to attending any programs $(p=0.09)$. Following the intervention, DAS increased to 105.8 (SD 11.0) among all students, and was similar among the students completing 2 preintervention assessments ( $p \leq 0.01$ all comparisons). Overall, students demonstrated greater increase on measures of dementia comfort (5.9-point increase, $p<0.01$ ) compared with dementia knowledge (2.6-point increase, $p<0.05$ ). Qualitatively, student responses collected at follow-up corroborated the favorable DAS response (table 1 and table e- 1 on the Neurology) ${ }^{\circledR}$ Web site at Neurology.org).

DISCUSSION These pilot findings indicate significant gains in medical student dementia attitudes, particularly comfort, following brief attendance at existing museumbased programs. These programs, which are becoming increasingly popular and ubiquitous, are feasible and could have a considerable impact on subsequent clinical encounters, providing a better understanding of how patients and caregivers experience meaningful relationships and sustain quality of life. Anecdotally, such programs could inform career choices, given the unique experiences they provide.

Interdisciplinary psychosocial support programs including art-centered experiences can provide a meaningful and lasting benefit to patients with dementia and their caregivers. These programs rely on preserved abilities, provide a vehicle for nonverbal emotional expression, and develop a state of flow (concentration and pleasure derived from an intrinsically rewarding activity), leading to a sense of well-being. ${ }^{7}$ Including a medical student in such an experience could improve his or her understanding of existing community-based programs to complement aspects of palliative care strategies. 
Table 1 Dementia Attitudes Scale responses of preclinical medical students before and after program participation

\begin{tabular}{|c|c|c|c|}
\hline \multirow[b]{2}{*}{ Dementia Attitudes Scale } & \multicolumn{2}{|c|}{ Before intervention, mean (SD) } & \multirow[b]{2}{*}{$\begin{array}{l}\text { After program } \\
\text { attendance, } \\
\text { post-test }\end{array}$} \\
\hline & $\begin{array}{l}\text { Baseline } 1 \text { (all } \\
\text { participants) }\end{array}$ & $\begin{array}{l}\text { Baseline } 2 \text { (for } \\
\text { subgroup, repeated } \\
\text { in } 2 \text { wk) }\end{array}$ & \\
\hline \multicolumn{4}{|l|}{ DAS total score } \\
\hline All students $(n=19)$ & 97.4 (11.2) & & $105.8(11.0)^{a}$ \\
\hline Single baseline only ( $n=9$ ) & 98.9 (13.9) & & $106.4(12.2)^{b}$ \\
\hline Repeated pretest $(n=10)$ & $95.7(7.7)$ & $98.7(7.4)^{d}$ & $105.1(10.0)^{\mathrm{c}}$ \\
\hline \multicolumn{4}{|l|}{ DAS subdomains } \\
\hline \multicolumn{4}{|l|}{ DAS comfort } \\
\hline All students $(n=19)$ & $39.5(6.7)$ & & $45.4(8.0)^{c}$ \\
\hline Single baseline only $(n=10)$ & $40.6(8.6)$ & & $45.8(8.6)$ \\
\hline Repeated pre-test $(\mathrm{n}=9)$ & $38.3(3.9)$ & $39.7(4.9)^{d}$ & $44.9(7.8)^{b}$ \\
\hline \multicolumn{4}{|l|}{ DAS knowledge } \\
\hline All students $(n=19)$ & $57.8(5.4)$ & & $60.4(5.2)^{b}$ \\
\hline Single baseline only ( $n=10)$ & $58.3(6.2)$ & & $60.6(6.0)$ \\
\hline Repeated pretest $(n=9)$ & $57.3(4.7)$ & $59.0(3.6)$ & $60.2(4.4)$ \\
\hline
\end{tabular}

Dementia Attitudes Scale (DAS) score ranges from 20 (least favorable) to 140 (most favorable). All comparisons use within-subject $t$ test comparison of means.

Baseline 1 vs post-test: ${ }^{a} p<0.001,{ }^{b} p<0.05,{ }^{c} p<0.01$. Baseline 2 vs post-test: ${ }^{d} p<$ 0.05. All other comparisons $p>0.05$.

Our study has several strengths. We minimized the potential bias of repeated testing; taking the survey twice had no meaningful impact on DAS before the intervention. Also, despite the brief intervention period of a single 90-minute session in our study, DAS increased significantly between 8 to 10 points. For comparison, another study involving medical students in a 4-week program had a 16-point DAS improvement, also with greater changes in comfort than knowledge. ${ }^{5}$ Notably, our program occurred during a period in training unlikely to detract substantially from other educational efforts.

We acknowledge several limitations to our study. Our study included a small sample size from a single school in a metropolitan area with well-established museum programs; expanding such programs to schools without similar existing programs may be impractical. A participant bias is possible; students who may have been more likely to have an interest in dementia could have volunteered and been more likely to acknowledge a positive experience. A study involving all students in a single class, several schools, or a longitudinal study including several academic years could help clarify or resolve this issue. Additionally, our study lacked a control group and baseline DAS was used as a proxy for the control condition.

Other community-based nonclinical health program models have an important educational role in improving student perceptions of chronic disease management.
Some schools require attendance at an established Alcoholics Anonymous open meeting ${ }^{8}$ to complement understanding of and attitudes toward alcoholism. The impact of early formative experiences in alcoholism and other complex, chronic neuropsychiatric disorders including dementia could substantively impact attitudes and career choices of physicians in training, across the continuum of learning and care of these patients, arguing for further development and incorporation of these approaches in medical school curricula.

\section{AUTHOR CONTRIBUTIONS}

Hannah J. Roberts: drafting/revising the manuscript, study concept or design, analysis or interpretation of data, accepts responsibility for conduct of research and final approval, acquisition of data, statistical analysis, study supervision, obtaining funding. James Noble: drafting/revising the manuscript, study concept or design, analysis or interpretation of data, accepts responsibility for conduct of research and final approval, statistical analysis, study supervision.

\section{ACKNOWLEDGMENT}

The authors thank Carolyn Halpin-Healy (of Arts \& Minds) and Rebecca McGinnis (of the Metropolitan Museum of Art) for assistance in program development.

\section{STUDY FUNDING}

H.J. Roberts was funded by the Steve Miller Fellowship in Medical Education (Columbia University). Dr. Noble received no direct funding for participation in this research.

\section{DISCLOSURE}

H. Roberts reports no disclosures relevant to the manuscript. J. Noble serves in a volunteer capacity as the president of Arts \& Minds, which served as the vehicle for 2 of the 4 program sites. The effect of Arts \& Minds vs other program sites was not explored in this research. Dr. Noble's relationship with this project was reviewed by the Columbia University Conflict of Interest Committee and considered to not pose a significant conflict of interest to this work. Go to Neurology.org for full disclosures.

\section{REFERENCES}

1. Hebert LE, Scherr PA, Bienias JL, Bennett DA, Evans DA. Alzheimer disease in the US population: prevalence estimates using the 2000 census. Arch Neurol 2003;60:1119-1122.

2. Mohamed S, Rosenheck R, Lyketsos CG, Schneider LS. Caregiver burden in Alzheimer disease: cross-sectional and longitudinal patient correlates. Am J Geriatr Psychiatry 2010;18:917-927.

3. Nagle BJ, Usita PM, Edland SD. United States medical students' knowledge of Alzheimer disease. J Educ Eval Health Prof 2013;10:4.

4. Jefferson AL, Cantwell NG, Byerly LK, Morhardt D. Medical student education program in Alzheimer's disease: the PAIRS Program. BMC Med Educ 2012;12:80.

5. George DR, Stuckey HL, Whitehead MM. An arts-based intervention at a nursing home to improve medical students' attitudes toward persons with dementia. Acad Med 2013;88:837-842.

6. O'Connor ML, McFadden SH. Development and psychometric validation of the dementia attitudes scale. Int J Alzheimers Dis 2010;2010.

7. Chancellor B, Duncan A, Chatterjee A. Art therapy for Alzheimer's disease and other dementias. J Alzheimers Dis 2014;39:1-11.

8. Stack KM, Fore Arcand LG, Briscoe G. Use of alcoholics anonymous as part of medical school education: students' and educators' perspectives. Subst Abus 2012;33:387-391. 


\section{Neurology}

\section{Education Research: Changing medical student perceptions of dementia: An arts-centered experience}

Hannah J. Roberts and James M. Noble

Neurology 2015;85;739-741 Published Online before print July 29, 2015

DOI 10.1212/WNL.0000000000001867

\section{This information is current as of July 29, 2015}

\section{Updated Information \& Services \\ Supplementary Material}

\section{References}

Citations

Subspecialty Collections

Permissions \& Licensing

Reprints including high resolution figures, can be found at: http://n.neurology.org/content/85/8/739.full

Supplementary material can be found at: http://n.neurology.org/content/suppl/2015/07/29/WNL.0000000000001 867.DC1

http://n.neurology.org/content/suppl/2015/07/29/WNL.0000000000001 867.DC2

This article cites 7 articles, 0 of which you can access for free at: http://n.neurology.org/content/85/8/739.full\#ref-list-1

This article has been cited by 1 HighWire-hosted articles: http://n.neurology.org/content/85/8/739.full\#\#otherarticles

This article, along with others on similar topics, appears in the following collection(s):

All Cognitive Disorders/Dementia

http://n.neurology.org/cgi/collection/all_cognitive_disorders_dementia Other Education

http://n.neurology.org/cgi/collection/other_education

Quality of life

http://n.neurology.org/cgi/collection/quality_of_life

Information about reproducing this article in parts (figures,tables) or in its entirety can be found online at:

http://www.neurology.org/about/about_the_journal\#permissions

Information about ordering reprints can be found online:

http://n.neurology.org/subscribers/advertise

Neurology ${ }^{\circledR}$ is the official journal of the American Academy of Neurology. Published continuously since 1951, it is now a weekly with 48 issues per year. Copyright (C 2015 American Academy of Neurology. All rights reserved. Print ISSN: 0028-3878. Online ISSN: 1526-632X.

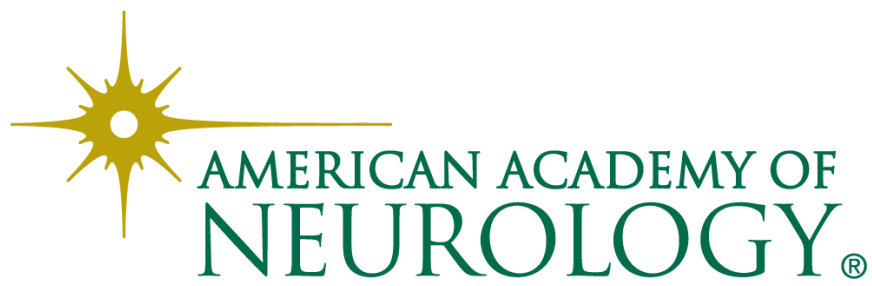

